\title{
Characteristics of drought propagation in South Korea: relationship between meteorological, agricultural, and hydrological droughts
}

\author{
Hyedeuk Bae ${ }^{1}$ (D) Heesook $\mathrm{Ji}^{1} \cdot$ Yoon-Jin $\mathrm{Lim}^{1} \cdot$ Young Ryu ${ }^{1} \cdot$ Moon-Hyun Kim ${ }^{1}$. \\ Baek-Jo Kim ${ }^{1}$
}

Received: 1 March 2017 / Accepted: 17 July 2019 / Published online: 20 September 2019

(C) The Author(s) 2019

\begin{abstract}
To investigate the propagation of meteorological droughts to agricultural and hydrological droughts, the relationship between droughts was analyzed using observed precipitation and agricultural reservoir and dam storage levels with SPI from 1998 to 2015 in South Korea. For the relationship between different types of droughts, we find that the occurrence of meteorological droughts after concentrated precipitation in the wet season (from June to September) tends not to lead to agricultural or hydrological droughts. A lack of precipitation from April to September, when large volumes of irrigation water are consumed, triggers both meteorological and agricultural droughts. In the case of hydrological droughts propagated from meteorological droughts, precipitation deficits in the dry season (between October and March) caused decrease in dam storage levels only. The occurrence of all different types of droughts is associated with extreme meteorological droughts, which are mainly caused by precipitation deficits in the wet season or prolonged rainfall shortages; in these cases, meteorological droughts led to agricultural and hydrological droughts. An analysis of the seasonal characteristics of storage level changes that in the wet season, agricultural reservoir storage levels are more dependent on precipitation deficits than dam storage levels. On other hand, when precipitation deficits were recorded in the dry season, agricultural reservoir storage levels went up, but dam storage levels dropped. The propagation of meteorological droughts to agricultural and hydrological droughts depends not only on drought severity but also on the drought timing. These findings may contribute to establishing a comprehensive drought monitoring system.
\end{abstract}

Keywords Propagation · Drought type $\cdot$ SPI (standardized precipitation index) $\cdot$ Storage level · Precipitation

Moon-Hyun Kim

gpemro@gmail.com

1 National Institute of Meteorological Sciences, KMA, Jeju-do, South Korea 


\section{Introduction}

Droughts are one of the most serious natural disasters which are characterized by widespread, prolonged damage to various aspects of the environment, society, and economy. Damage from droughts is a consistent problem for many countries around the world. For example, drought damage in the USA is thought to exceed an average of $\$ 10$ billion per event (NCDC 2016). In an attempt to better understand and more effectively respond to droughts, many studies have been conducted around the world to investigate the periodicity of droughts (Nicholson 1983; Meshcherskaya and Blazhevich 1997; Cancelliere and Salas 2010) and the atmospheric processes associated with droughts (Mo et al. 1997; Naithani et al. 2012; Stoll et al. 2013); other studies have analyzed teleconnection patterns associated with droughts (Chiew et al. 1998; Zhu et al. 2010; Choi et al. 2013; Wang et al. 2015) and have developed a drought index (Palmer 1965; Mckee et al. 1993).

Droughts can be generally classified into four closely related categories: meteorological, agricultural, hydrological, and socioeconomic (Wilhite and Glantz 1985). Meteorological droughts can be determined and defined according to precipitation deficits, and these droughts can lead to other types of droughts. Agricultural drought links various characteristics of meteorological drought to agricultural impacts, focusing on precipitation shortages, differences between actual and potential evapotranspiration, soil water deficits, and reduced reservoir levels (Botterill and Fisher 2003). Hydrological droughts refer to a lack of water in the hydrological system and it can be defined as reduced river flow as well as decreasing water levels of dams, lakes, and underground water on the basin scale (Kumaz 2014). Socioeconomic droughts can be defined as economic, social, and environmental damages caused by different types of droughts. There have been many comparative analyses and studies focused on linking drought indices to drought types to allow a more comprehensive understanding of the relationships between different drought types (Keyantash and Dracup 2002; Vasiliades and Loukas 2009; Vicente-Serrano et al. 2012). Research was conducted with a focus on the integration of multiple drought indices for establishing comprehensive drought information system; an example is the development of a single drought index from existing meteorological, agricultural, and hydrological indices (Brown et al. 2008; Karamouz et al. 2009; Mo and Lettenmaier 2014; Rajsekhar et al. 2015; Hao et al. 2016). Also, Huang et al. (2017) and Leng et al. (2015) studied the propagation from meteorological drought to agricultural and hydrological droughts in China using the correlation and comparison among each type of drought index. Such studies have proved useful for applicability assessments and understanding the relationships between each drought index, but using only drought indices is inadequate for a thorough understanding of drought characteristics and propagation between drought categories. It is desirable to understand observation-based drought relationships and how they can serve as the foundation of a drought response assessment. Drought propagation process, which is necessary for establishing comprehensive drought monitoring systems, requires further study using long-term observations to evaluate each type of drought.

Recently, the Korean Peninsula has faced severe droughts for more than 3 years (2013-2015); during this period, the annual precipitation was less than 35-50\% of normal levels (Kwon et al. 2016). Droughts on the Korean Peninsula are more likely when the summer monsoon season is relatively short (Zhang and Zhou 2015). In South Korea, precipitation is normally concentrated in the summer, when $70 \%$ of precipitation usually occurs. For this reason, the water supply in South Korea is managed through the operation of reservoirs or dams; the government agencies responsible for responding to agricultural 
and hydrological droughts assess and mitigate droughts based on the observed storage levels in these agricultural reservoirs and dams. In this regard, an analysis of agricultural reservoir and dam storage levels based on precipitation deficits is needed to understand the propagation of different types of droughts.

Therefore, this study attempts to identify the propagation of meteorological droughts to agricultural and hydrological droughts in South Korea based on long-term observation of precipitation, agricultural reservoir and dam storage levels. First, regional precipitation characteristics are briefly reviewed, and then meteorological droughts are analyzed using SPI (standardized precipitation index). Case studies are then considered using precipitation and storage levels in South Korea to identify the propagation of meteorological to agricultural and hydrological droughts.

\section{Methods and data}

\subsection{Analysis methods}

1. Precipitation analysis

A principal component analysis (PCA) has been applied to the observed precipitation in Korea to identify regional precipitation variability. PCA is a standard statistical method which transforms an original set of intercorrelated variables into a small number of new, linearly uncorrelated variables that can explain most of the total variance in the data (Rencher 1998). The uncorrelated variables are called principal components, and they consist of linear combinations of the original variables. This method is often used in meteorological studies (Esteban-Parra et al. 1998; Powell and Keim 2015).

PCA shows that there are regional variations in precipitation in Korea (discussed in Sect. 3.1), so Korea was split into four regions according to regional precipitation characteristics using a K-means clustering algorithm. K-means clustering is a method which classifies data based on a similarity or distance calculation. This method is applicable to many research fields, including several precipitation-based cluster classification studies (Avila and Alarcon 1999; Liu and Yin 2001; Nuissier et al. 2011; Yoo et al. 2012).

\section{Droughts definitions}

In this study, the following droughts were taken into consideration: meteorological droughts whose SPI (standardized precipitation index) values were below -1.0, agricultural droughts where agricultural reservoir storage levels fell below $75 \%$ of normal agricultural reservoir storage levels, and hydrological droughts where dam storage levels fell below $75 \%$ of normal dam storage levels.

For meteorological droughts, the SPI is commonly used by the KMA (Korea Meteorological Administration) for droughts status assessment and forecasting. Table 1 defines drought categories according to SPI. SPI can be calculated over multiple timescales (i.e., $3,6,12$, or 24 months). Previous research using Receiver operating characteristic (ROC) curves found a correlation between SPI3 (the 3-month SPI) and drought occurrence appears to be stronger than it is among SPI6, 9, 12, PDSI (Palmer Drought Severity Index), percent of normal precipitation, temperature, and evapotranspiration on the Korean Peninsula, indicating that SPI3 is the most useful drought index for analyzing droughts in South Korea (Kim and Lee 2011). Therefore, this study uses SPI3 to analyze meteorological 
Table 1 Drought classifications by SPI value (Mckee et al. 1993)

\begin{tabular}{ll}
\hline SPI value & Drought category \\
\hline-1.00 to -1.49 & Moderate drought \\
-1.50 to -1.99 & Severe drought \\
-2.0 and less & Extreme drought \\
\hline
\end{tabular}

droughts. For the agricultural drought, most of these indices are derived from soil moisture deficiency based on precipitation and air temperature (Palmer 1968; Mishra and Singh 2010). However, the soil moisture in irrigated areas relies not only on local precipitation but also the withdrawal of water from reservoirs when available ( $\mathrm{Li}$ et al. 2016). South Korea has 752,598 ha of irrigated land that is devoid of observed soil moisture for spatial and temporal agricultural drought assessment. Therefore, the KRCC (Korea Rural Community Corporation) monitors and predicts agricultural droughts using storage levels of agricultural reservoirs which is designed to supply water for irrigation and to prevent agricultural damage from droughts. Furthermore, Jang et al. (2004) and Nam et al. (2013) studied agricultural drought assessments using reservoirs in South Korea. In consideration of these reason, we deem that the assessment of long-term spatial and temporal agricultural droughts in South Korea using agricultural reservoir levels is appropriate. For hydrological drought, The MOLTI (Korean Ministry of Land, Infrastructure and Transport) which has primary responsibility for the response to hydrological droughts, assesses, and monitors hydrological drought using dams on South Korea. Therefore, we analyze hydrological drought using dam levels which can be represented in each basin within South Korea.

To define agricultural and hydrological droughts for analysis of characteristics, the threshold should be chosen such as long-period mean (or median) of the variable of interest (Clausen and Pearson 1995) that it is considered to represent the water demand level (Yevjevich et al. 1983; Rossi 2000). The KRCC studied the occurrence of agricultural droughts by reviewing cases where agricultural reservoir storage levels fell below $75 \%$ of average storage levels (Lee et al. 2016). The MOLTI (2009) analyzed the occurrence of hydrological droughts when dam storage levels fell below $75 \%$ of average storage levels. Therefore, we conducted seven case studies about the relationship between drought impacts and storage levels from 1998 to 2015. During this time, agricultural damage occurred between 1200 and 58,000 ha of agricultural areas in South Korea (the average agricultural damage was 17,400 ha) and the agricultural reservoir levels ranged between 35.5 and $74.3 \%$ with respect to the normal storage level. Furthermore, during the same period, the dam levels ranged between 48.5 and $72.8 \%$ of the normal storage level at which time the MOLTI enforced restriction on dam water supply. Thus, $75 \%$ of the normal storage level was considered as threshold level. In this study, "normal storage level" refers to the 18-year average of storage levels (from 1998 to 2015).

\subsection{Data}

In this study, drought characteristics on the Korean Peninsula were identified and reviewed using monthly observed precipitation and agricultural reservoir and dam storage level data. The precipitation data were collected from 59 ASOS (Automated Synoptic Observing System) stations operated by the KMA; these stations provide data from 1973 to 2015 , data time series over the 30 years are generally needed to find climatological trends and to produce SPI values. The storage level data were taken from 153 of the 354 agricultural 
reservoirs monitored by the KRCC for the response to agricultural droughts (2012 KRCC Report), which have agricultural reservoir storage capacity greater than $600 \times 10^{3} \mathrm{~m}^{3}$. A total of 4 dams (out of the 15 multi-purpose dams monitored by the MOLTI for hydrological drought mitigation measures in 2009) were also selected for their representativeness of each basin. The locations from which agricultural reservoir and dam storage level data were collected based on the availability of observed data during 1998-2015 are shown in Fig. 1, along with the locations of the ASOS stations.

\section{Results}

\subsection{Regional precipitation characteristics}

Prior to the analysis of droughts, a PCA was conducted to understand the direct impact of precipitation characteristics (Fig. 2). The first mode (PC1, 40.5\%) demonstrates opposing precipitation patterns in the northern and southern areas. The time series of PC1 shows a pattern of north-south precipitation changing on a 1- or 2-year basis from 1975 to 1995. In the mid-1990s, this change cycle lengthened; the southern area received more rain from 1999 to 2004 and from 2014 to 2015, while the northern area received more rain from 2006 to 2011. The second mode (PC2, 26.1\%) shows the contrasting pattern of precipitation between eastern and western areas. The PC2 time series indicates a 4- or 5-year basis, suggesting more prolonged precipitation pattern changes compared to PC1. The precipitation in the western area was relatively high from 1979 to 1987, then the eastern area received more rain from 1988 to 2006; the precipitation in the western area was once again higher from 2007 to 2015.

Given the regional differences in precipitation patterns observed through PCA, a K-means clustering analysis was conducted to facilitate regional drought analysis. The area was categorized into four regions (A, B, C, and D) according to annual and seasonal precipitation. Region D, the lowest latitude region, had the highest average annual precipitation, $1480 \mathrm{~mm}$. Region C, impacted by its mountainous terrain, received $1069 \mathrm{~mm}$ of average annual precipitation, the lowest amount of any region (Fig. 3a). The average annual precipitation in Regions A and B were $1341 \mathrm{~mm}$ and $1266 \mathrm{~mm}$, respectively. An analysis
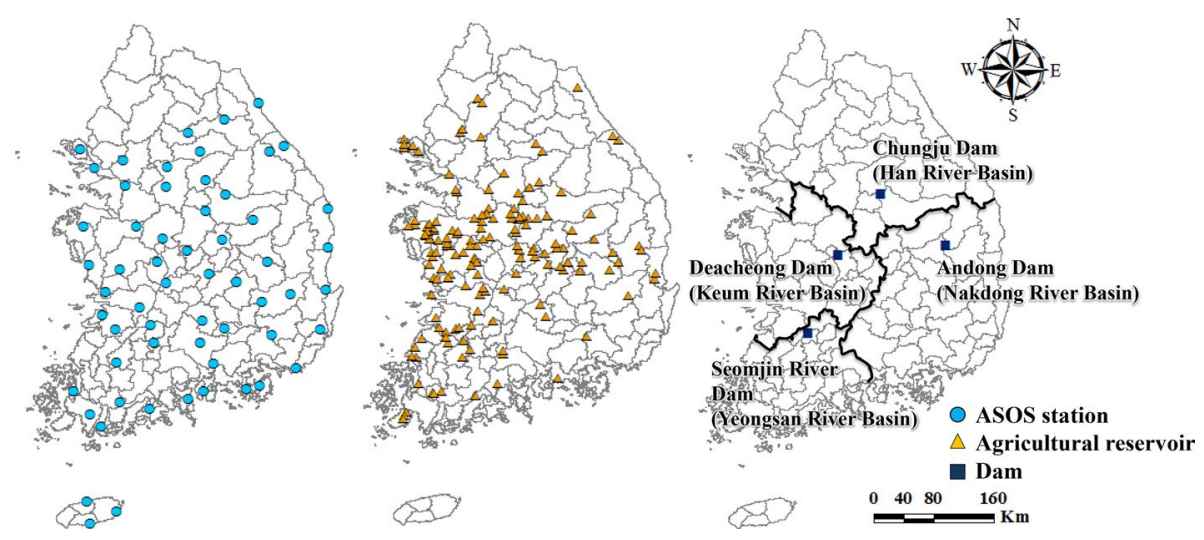

Fig. 1 Locations of ASOS stations, agricultural reservoirs and dams in South Korea used for this study 

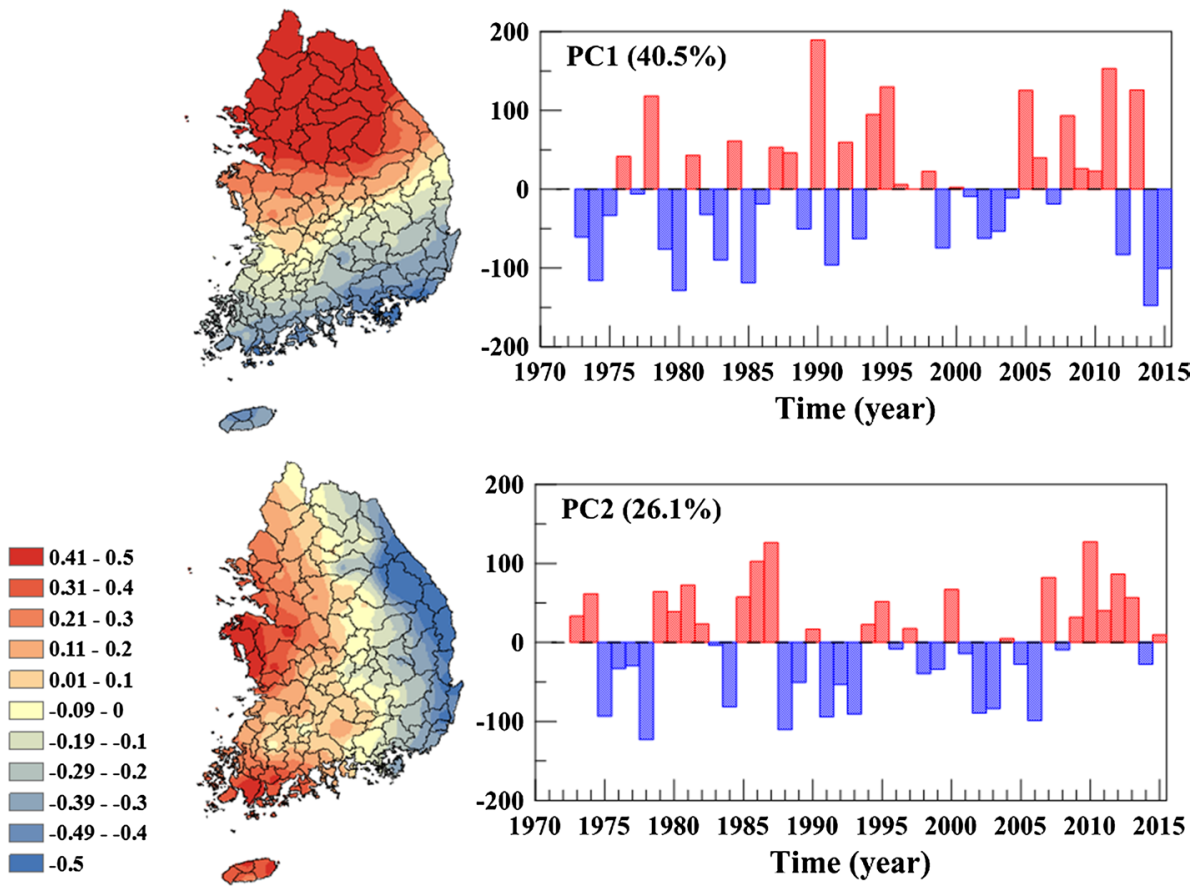

Fig. 2 Spatial distribution patterns for the two principal components, PC1 (top panel) and PC2 (bottom panel), computed for multi-annual precipitation
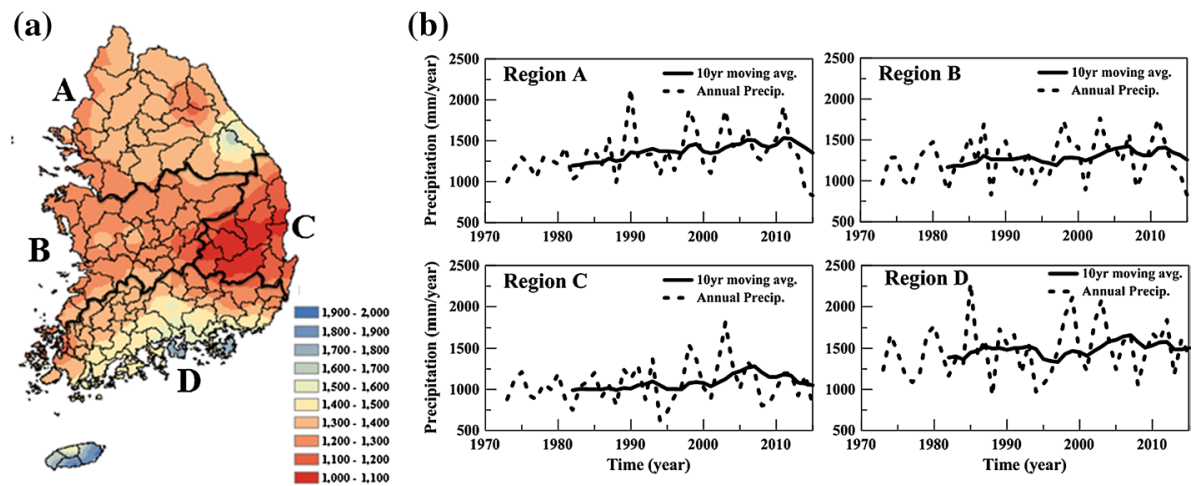

Fig. 3 Geographical distribution of the average annual precipitation in $\mathrm{mm}$ (a) and time series of regional precipitation trends $(\mathbf{b})$

of the time series of regional precipitation using a 10-year average of annual precipitation (Fig. 3b) shows similar trends for Regions A and B since the 1990s; precipitation grows from 1980 to 2013. Regions C and D share precipitation trends with precipitation decreasing in the mid-1990s, then increasing until the mid-2000s before decreasing again. The regional classification based on K-means clustering reflects these regional precipitation characteristics. 


\subsection{Meteorological drought trends}

Meteorological droughts tend to precede all other droughts and thus play a significant role in the occurrence of other types of droughts. Because of this, analyzing meteorological droughts are important for identifying relationships among different types of droughts. Here, meteorological drought trends were examined in detail using SPI3.

SPI3 values were calculated, and the frequency of annual drought occurrence (SPI3 values less than -1.0) was analyzed based on the five different time periods (1973-1979, 1980-1989, 1990-1999, 2000-2009, and 2010-2015) shown in Fig. 4. To facilitate comparisons among these time periods, a normalized "annual drought frequency" was defined to be the drought frequency per year over each period. The annual drought frequency was 2.05 from 1973 to $1979,2.01$ in the $1980 \mathrm{~s}, 1.78$ in the $1990 \mathrm{~s}$, 1.95 in the $2000 \mathrm{~s}$, and 2.19 from 2010 to 2015 . The frequency of droughts decreased continuously from the 1970s to the 1990s, but it began to slowly increase as of the 2000 s, reaching a peak in the 2010s. Spatial analysis of the annual drought frequency reveals that Region A had a high frequency of droughts in the 1970s and the 2010s, while Region D had a high drought frequency in the 1990s and the 2000s. In the 1980s, drought frequencies were quite balanced between all regions.

Table 2 gives the seasonal drought frequencies and annual drought frequencies as a function of severity for each time period. In the 1980s and 2000s, droughts occurred at highest frequency during spring, whereas droughts were most frequent in the summer in the 1970s and 2010s and during winter in 1990s. When droughts are separated by severity (based on SPI3, see Table 1), both moderate and extreme droughts were most frequent in the 1980s, while severe droughts were most frequent in the 1990s. A comparison of seasonal frequency and drought severity shows that more frequent droughts in spring tend to result in more frequent extreme droughts (the 1980s and the 2000s). Precipitation deficits that occur in winter and persist until spring can trigger extreme meteorological drought because precipitation is concentrated in the summer monsoons.

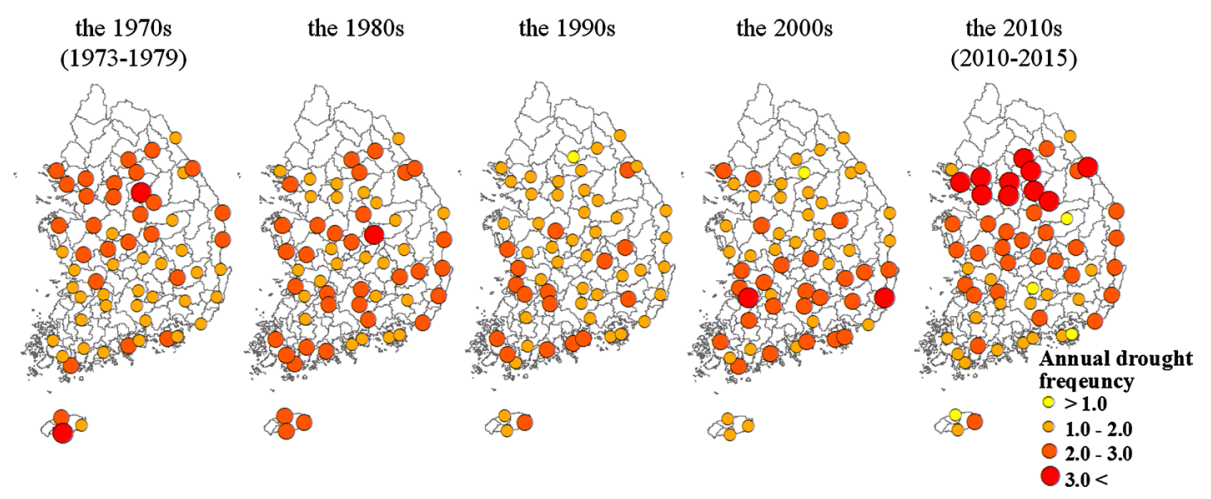

Fig. 4 Geographical distribution of annual drought frequency (calculated using SPI3) over five different time periods 
Table 2 Seasonal drought frequency and annual drought frequency as a function of severity for each time period

\begin{tabular}{cllllll}
\hline & & The 1970s & The 1980s & The 1990s & The 2000s & The 2010s \\
\hline Seasonal drought frequency & Spring & 2.5 & $\mathbf{7 . 2 5}$ & 2.5 & $\mathbf{7}$ & 0.75 \\
& Summer & $\mathbf{5 . 5}$ & 4.5 & 4.5 & 1.25 & $\mathbf{5 . 2 5}$ \\
& Fall & 4.75 & 3.25 & 5.5 & 5.25 & 1.75 \\
& Winter & 4.75 & 5.25 & $\mathbf{6 . 2 5}$ & 4.5 & 2.75 \\
Annual drought frequency & $>-1$ & 2.03 & 2.06 & 1.90 & 1.89 & 1.84 \\
by severity (SPI3 values) & -1.5 to -1 & 1.11 & 1.23 & 1.00 & 1.03 & 1.04 \\
& -2.0 to -1.5 & 0.71 & 0.40 & 0.80 & 0.53 & 0.63 \\
& $>-2.0$ & 0.21 & $\mathbf{0 . 4 3}$ & 0.10 & $\mathbf{0 . 3 3}$ & 0.17 \\
\hline
\end{tabular}

\subsection{The propagation of meteorological droughts to agricultural and hydrological droughts}

SPI3 values and agricultural reservoir and dam storage levels were used to identify a relationship among meteorological, agricultural, and hydrological droughts. To determine occurrence rates for each type of drought, time series analysis was conducted using SPI3 values and accumulated agricultural reservoir and dam storage level deficits (the difference between actual storage and normal storage levels); this is shown in Fig. 5 for each region. An analysis of the different drought types reveals a wide variety of drought cases: meteorological droughts only (Case I; gray-shaded areas in Fig. 5), propagation from meteorological to agricultural drought (Case II; yellow), propagation from meteorological to hydrological drought (Case III; blue), and the occurrence of all types of droughts (Case IV; red). Table 3 lists the years and regions for each occurrence of these different drought cases.

To identify propagation from meteorological droughts to agricultural and hydrological droughts, an analysis of the different drought cases was conducted using data from the Daecheong Dam, located in the center of Region B, as well as from the large number of agricultural reservoirs in Region B (Fig. 6). In January 2011, Region B experienced a severe Case I meteorological drought (SPI3 = - 1.57). This was due to precipitation deficits (below normal precipitation) from October to November in 2010 and in January in 2011. However, the region had received adequate precipitation (140\% of normal precipitation) from August to September prior to this meteorological drought, resulting in a significant increase in agricultural reservoir and dam water levels. Consequently, the meteorological drought did not lead to agricultural and hydrological droughts. For the 2012 Case II drought, agricultural reservoir storage levels were relatively low until April due to low precipitation in September 2011. A moderate meteorological drought (SPI3 $=-1.34)$ and an agricultural drought (agricultural reservoir storage levels below $72 \%$ of normal storage) occurred in June due to the precipitation deficits in May and June, but dam storage levels were maintained above normal storage levels, so no hydrological drought occurred. For the 2009 Case III drought, despite a precipitation deficit from September to January, agricultural reservoir storage levels increased, whereas dam water levels decreased. A severe meteorological drought from November to January (SPI3 $=-1.60$ on average) led to the hydrological drought in April and May. (Dam storage levels were $72 \%$ of normal storage levels on average.) 

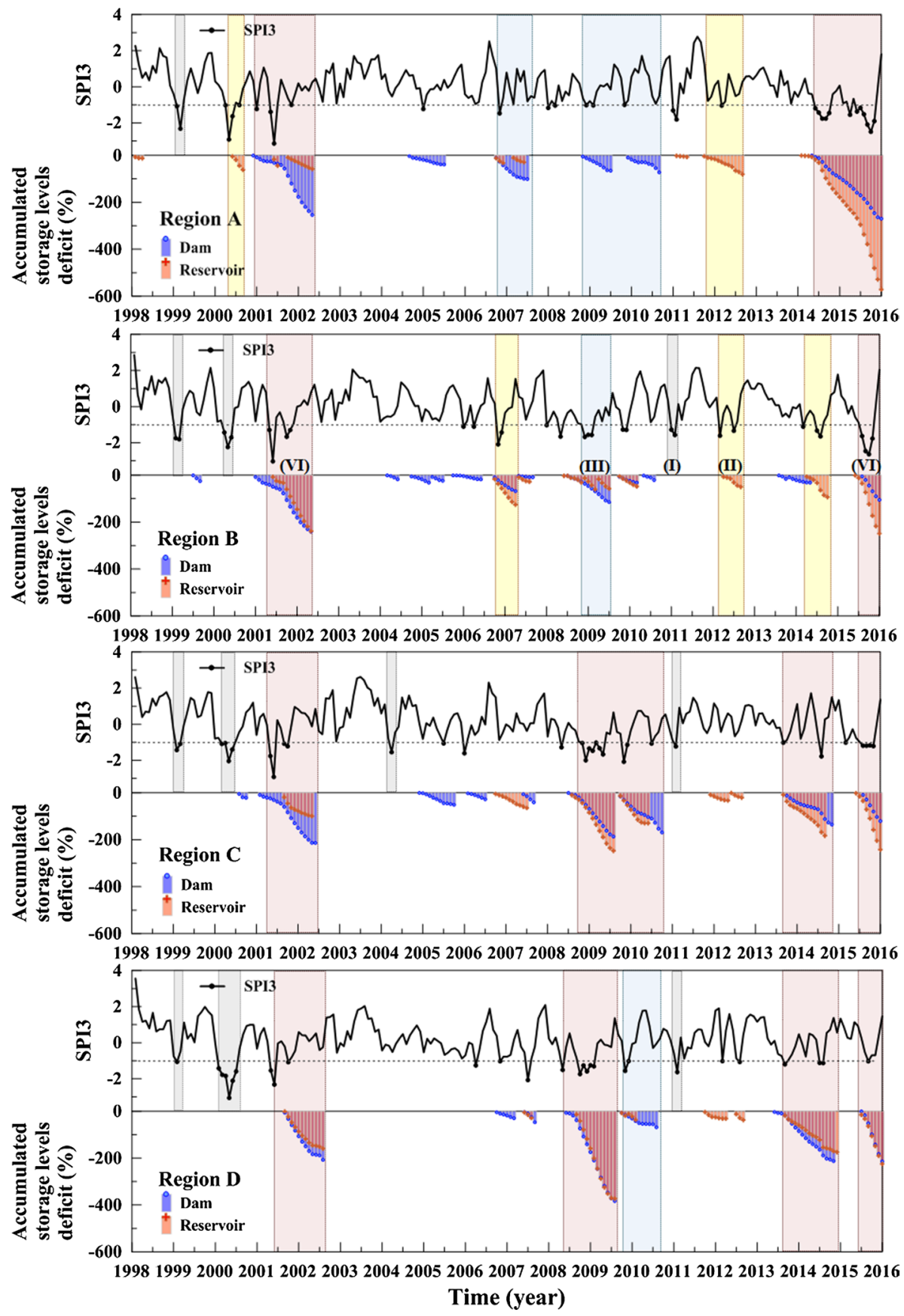

Fig. 5 Time series of SPI3 and accumulated agricultural reservoir and dam storage level deficits in each region. The shaded areas indicate occurrences of meteorological droughts only (gray, Case I), propagation from meteorological to agricultural drought (yellow, Case II), propagation from meteorological to hydrological drought (blue, Case III), and the occurrence of all types of droughts (red, Case IV) 
Table 3 Year and region of each case of drought occurrence

\begin{tabular}{|c|c|c|c|c|c|c|c|}
\hline \multicolumn{2}{|c|}{ Case I } & \multicolumn{2}{|c|}{ Case II } & \multicolumn{2}{|c|}{ Case III } & \multicolumn{2}{|c|}{ Case IV } \\
\hline Year & Region & Year & Region & Year & Region & Year & Region \\
\hline 999 & $\mathrm{~A}, \mathrm{~B}, \mathrm{C}, \mathrm{D}$ & 2000 & A & 2007 & A & 2001 & $\mathrm{~A}, \mathrm{~B}, \mathrm{C}, \mathrm{D}$ \\
\hline 2000 & $\mathrm{~B}, \mathrm{C}, \mathrm{D}$ & 2006 & B & 2009 & A, B & 2009 & C, D \\
\hline 2004 & $\mathrm{C}$ & 2012 & A, B & 2010 & $\mathrm{~A}, \mathrm{C}$ & 2014 & $\mathrm{~A}, \mathrm{C}, \mathrm{D}$ \\
\hline 2011 & $\mathrm{~B}, \mathrm{C}, \mathrm{D}$ & 2014 & B & & & 2015 & $\mathrm{~A}, \mathrm{~B}, \mathrm{C}, \mathrm{D}$ \\
\hline
\end{tabular}
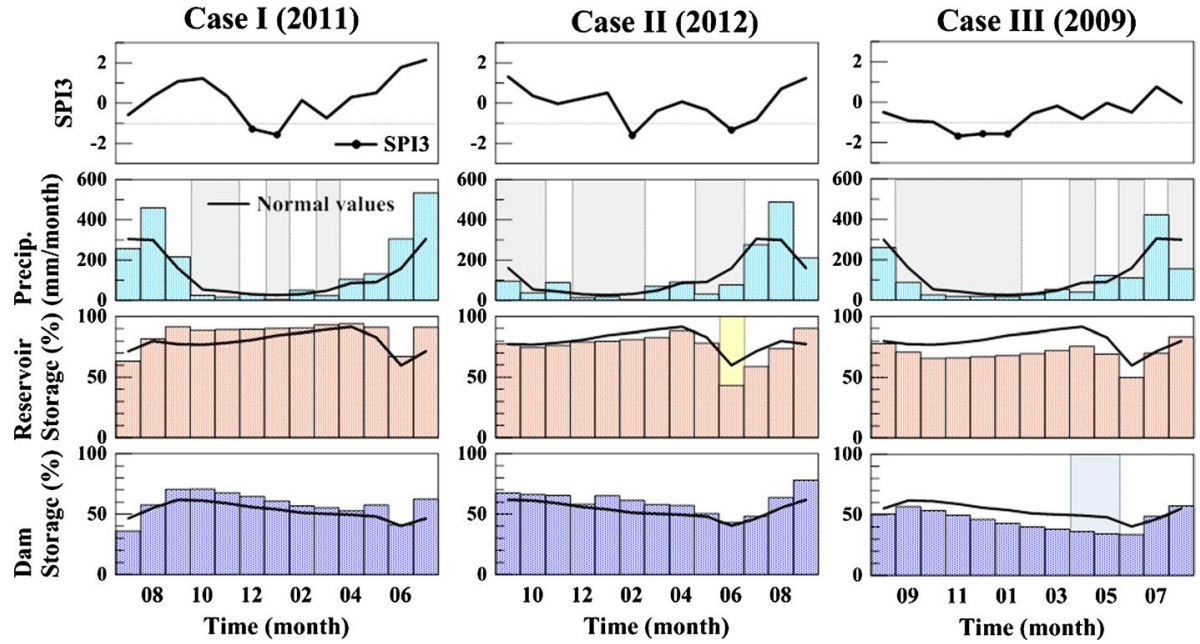

Fig. 6 Time series of SPI3, precipitation, and agricultural reservoir and dam storage levels for Cases I to III

A comparison analysis of the Case IV droughts in 2001 and 2015 was carried out (Fig. 7). In 2001, the hydrological droughts were more severe and prolonged than the agricultural droughts. The average agricultural drought severity was $66 \%$ of the normal storage levels over 7 months due to precipitation deficits in spring and summer (SPI3 $=-3.00$ in May). The average hydrological drought severity was $62 \%$ of the normal storage levels over 8 months; this was impacted by precipitation deficits from October to December in 2000 in addition to the 2001 meteorological droughts. In contrast, the agricultural droughts were observed to be more severe in the 2015 Case IV drought. Severe agricultural droughts occurred starting in July; drastic decreases in agricultural reservoir storage levels arose from precipitation deficits starting in May, which is when agricultural water requirements increase. The average agricultural drought severity was $49 \%$ of normal storage over 6 months. The average hydrological drought severity was $66 \%$ of the normal storage levels over 5 months due to the extreme meteorological drought that summer; the dam storage levels were maintained above normal storage levels until June 2015 by high precipitation (175\% of the normal precipitation) from October to December in 2014. The comparison of these two Case IV droughts shows that hydrological droughts can be more severe than agricultural droughts when precipitation deficits occur from October to March. Additionally, a meteorological drought of prolonged duration (more than 3 months) or increased severity in the summer leads to 

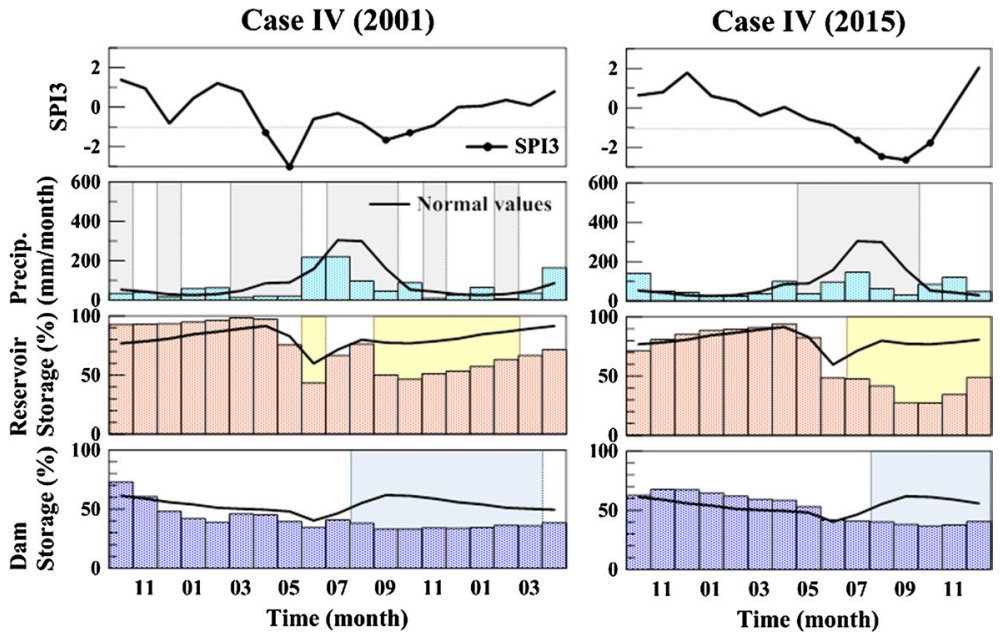

Fig. 7 The same as Fig. 6, except for Case IV

different types of drought. These drought propagation trends are similar across all the Regions studied (Fig. 5).

The case analysis indicates that meteorological droughts in fall/winter after large amounts of precipitation in summer do not necessarily lead to different agricultural or hydrological droughts. However, meteorological droughts from spring to summer can easily result in agricultural droughts. Furthermore, meteorological droughts in winter may cause hydrological droughts without agricultural droughts. When long-term meteorological droughts occur in spring and summer, they tend to trigger both agricultural and hydrological droughts. Therefore, the impact of meteorological droughts depends not only on drought severity but also on timing because of the seasonally variable characteristics of agricultural reservoir and dam storage levels.

\subsection{Characteristic of seasonal storage level changes}

To compare seasonal precipitation patterns and storage level changes, an analysis is conducted using standardized precipitation and agricultural reservoir and dam storage levels (Fig. 8). The precipitation, characterized by the summer monsoon pattern, is highest in July. Agricultural reservoir and dam levels are lowest in June due to high water consumption and low precipitation in April and May; they are highest in August and September due to the large volume of summer precipitation. To identify changes in storage levels due to seasonal precipitation, the months are separated into two groups: the wet season (from June to September) and the dry season (from October to March). In the wet season, both agricultural reservoir and dam storage levels tend to increase in response to the increase in precipitation, with a 1- to 2-month time lag. In the dry season, dam storage levels decrease due to low precipitation, whereas agricultural reservoir storage level increases.

To understand the relationship between seasonal storage level changes and precipitation, an analysis of storage levels changes in cases of seasonal precipitation deficits was conducted. Storage levels decreased by an average of $7.5 \%$ in agricultural reservoirs and $2.9 \%$ in dams when the wet season precipitation was $100 \mathrm{~mm}$ below the normal precipitation 
Fig. 8 Comparison between seasonal precipitation and agricultural reservoir and dam storage level changes

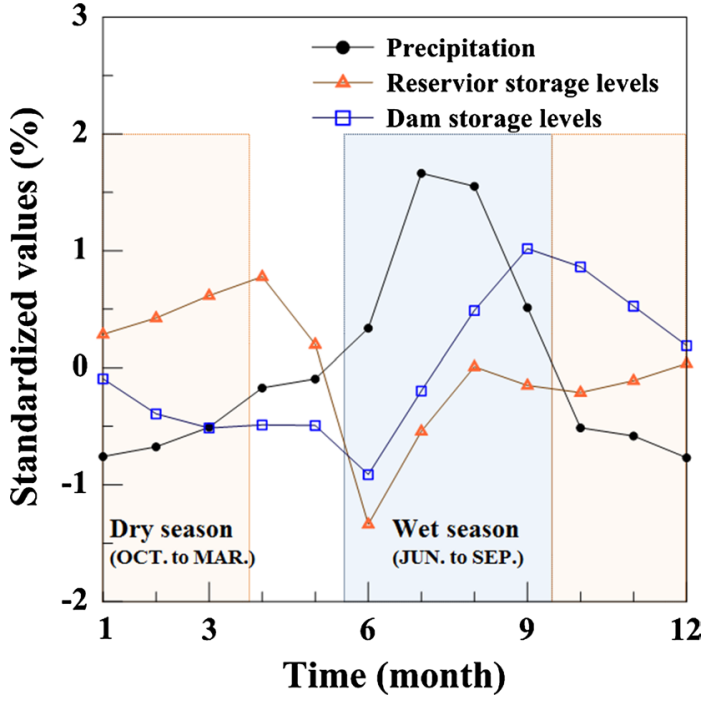

(Fig. 9). Changes in dam storage levels resulting from precipitation deficits were less likely than changes in agricultural reservoir storage levels, because the average dam storage capacity is estimated to be $1489 \times 10^{6} \mathrm{~m}^{3}$ compared to the $5.8 \times 10^{6} \mathrm{~m}^{3}$ estimated capacity of the agricultural reservoirs. On the other hand, precipitation deficits in the dry season still tended to result in increased agricultural reservoir storage levels, whereas dam storage levels decreased (Fig. 10); on average, agricultural reservoir storage levels increased by $1.4 \%$ and dam storage levels decreased by $4.6 \%$ when dry season precipitation was $30 \mathrm{~mm}$ below the normal value. This can be explained by the low demand for agricultural reservoir water for irrigation in winter and the high demand for the dam water for human consumption, industrial use, and navigability in the dry season. Region $C$ experienced a decrease in agricultural reservoir storage levels four times; this can be largely attributed to Region C's

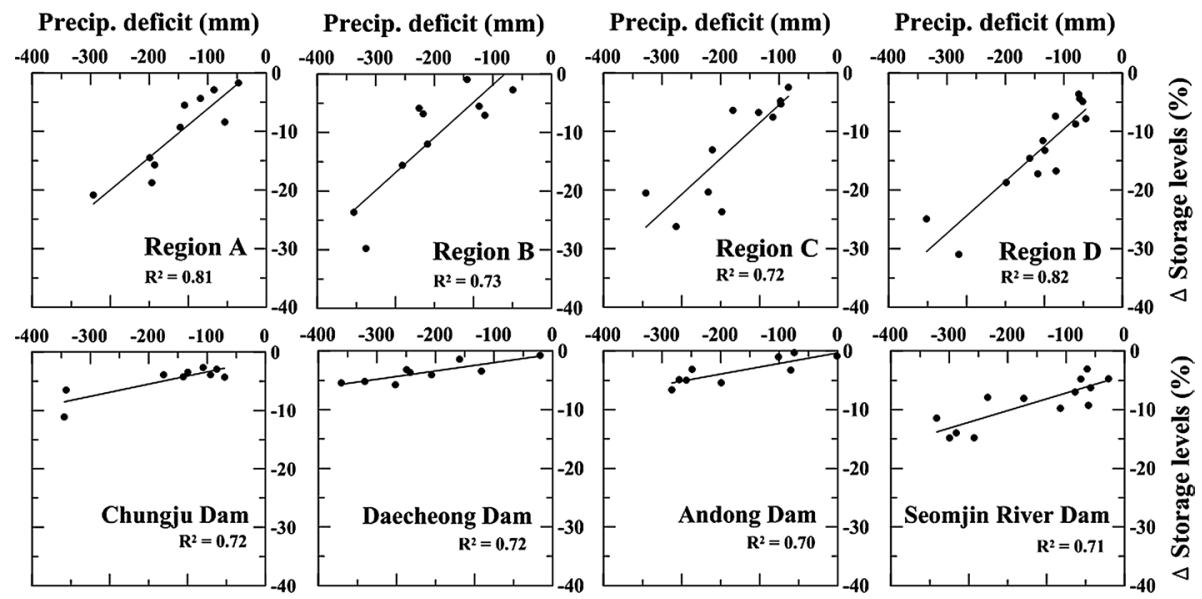

Fig. 9 Changes in agricultural reservoir and dam storage levels caused by precipitation deficits in the wet season 

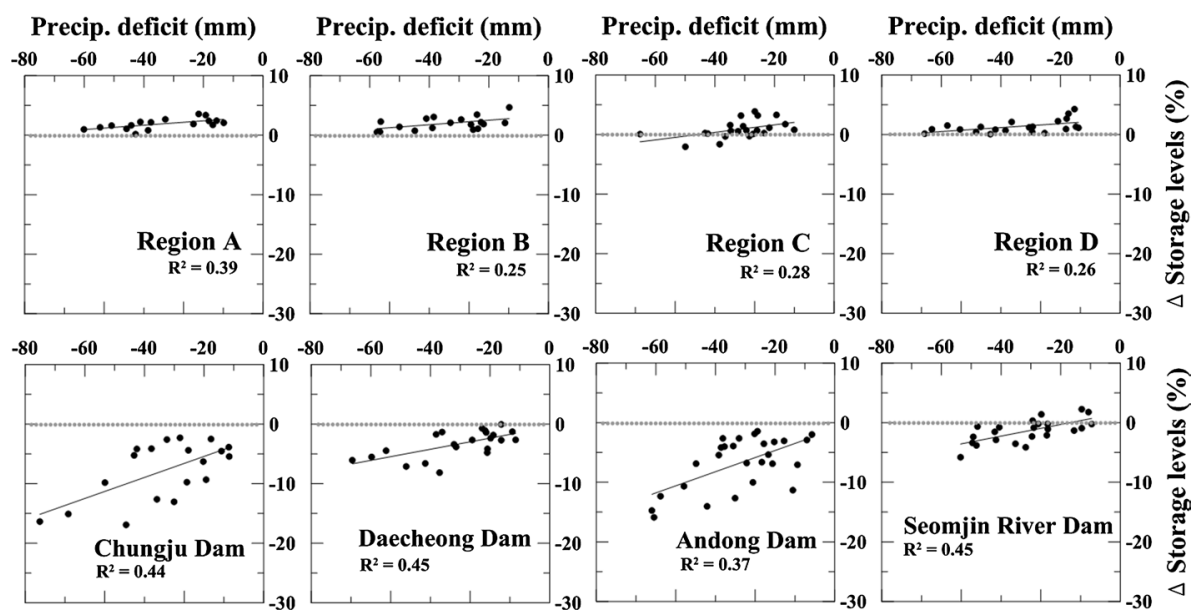

Fig. 10 Same as Fig. 9, except for the dry season

relatively small agricultural reservoirs (average capacity of $1.9 \times 10^{6} \mathrm{~m}^{3}$ ), which are easily affected by evaporation, etc. Examining the dams, the Seomjin River Dam has a relatively low frequency of storage level decreases; this can be explained by the fact that the Seomjin River Dam is primarily used for irrigation, despite being a multi-purpose dam.

The analysis of seasonal storage level changes indicates that agricultural reservoir storage levels are sensitive to precipitation in the wet season, resulting in more drastic changes than for dam storage levels. If precipitation shortages occur from March to September, when a large volume of agricultural water consumption is anticipated, it can lead to a severe agricultural drought. Hydrological droughts tend to be more severe than agricultural droughts, because agricultural reservoirs storage levels still tend to increase even when there are precipitation shortages in the dry season. The results of the drought case analysis (Sect. 3.3) are consistent with these findings for seasonal agricultural reservoir and dam storage level changes.

\section{Summary and conclusions}

In this study, the relationship among drought types was reviewed and explored using observed precipitation and agricultural and dam storage level data to identify the propagation of meteorological droughts to agricultural and hydrological droughts. Meteorological drought frequency was examined from 1973 to 2015 using SPI3. The annual drought frequency dropped from the 1970s (2.05) to the 1990s (1.78) and then began to increase as of the 2000s, reaching its peak in the 2010s (2.19). The frequency of different types of droughts was reviewed over the period between 1998 and 2015; meteorological, agricultural, and hydrological droughts did not necessarily occur concurrently in the same year. A case analysis of the relationship between different types of droughts and the seasonal characteristics of agricultural reservoir and dam storage level changes revealed the following:

1. When meteorological droughts occurred in winter after concentrated precipitation in the wet season (from June to September), agricultural and hydrological droughts did 
not occur; agricultural reservoir and dam storage levels were maintained at more than $75 \%$ of normal storage levels following concentrated precipitation.

2. In cases, where meteorological droughts propagated to agricultural droughts, precipitation deficits were recorded from March to September, when a large volume of agricultural water consumption was anticipated, meteorological droughts led to agricultural droughts.

3. In cases, where meteorological droughts propagated to hydrological droughts, the precipitation deficits in the dry season (from October to March) caused a decrease in dam storage levels (but not agricultural reservoirs), triggering hydrological droughts in spring or summer.

4. Cases where all different types of droughts coincided were associated with extreme meteorological droughts, largely due to precipitation deficits that occurred in the wet season or persisted for long periods of time; this resulted in agricultural and hydrological droughts due to the meteorological drought. If the precipitation deficit occurs from March to September, the agricultural drought is more severe than the hydrological drought, when precipitation deficits occur in the dry season, hydrological droughts are more severe due to the seasonal characteristics of agricultural reservoir and dam storage level changes.

5. Agricultural reservoir storage levels are more dependent on precipitation deficits than dam storage levels in the wet season. On the other hand, if precipitation deficits occur in the dry season, agricultural reservoir storage levels still increase, but dam storage levels decrease as a result of uninterrupted dam water consumption in winter.

How different types of droughts can be propagated from meteorological droughts depend not only on drought severity but also the timing of the drought. Drought propagation can be understood through analysis of the seasonal characteristics of agricultural reservoir, and dam storage level changes resulting from precipitation deficits; such analysis is easy and simple to use, facilitating an improved understanding of relationships between different drought categories for the regions where long-term observational data are recorded. Furthermore, understanding the relationship between meteorological, agricultural, and hydrological droughts will provide a foundation for establishing a comprehensive drought monitoring system in the regions studied here. Only precipitation and storage level data were used in this study due to the lack of available soil moisture and runoff data. For a more comprehensive analysis of droughts and agricultural reservoir and dam storage levels, further research must be conducted using additional data, such as soil moisture and runoff information.

Acknowledgements This research was funded by the Korea Meteorological Administration Research and Development Program 'Development of Climate Prediction System' under Grant (1365003054). I gratefully acknowledge assistance with data collection from Korea Rural Community Corporation and K-water. I am also immensely grateful to Dr. Adam W. DeMarco who provided expertise that greatly assisted the research.

Open Access This article is distributed under the terms of the Creative Commons Attribution 4.0 International License (http://creativecommons.org/licenses/by/4.0/), which permits unrestricted use, distribution, and reproduction in any medium, provided you give appropriate credit to the original author(s) and the source, provide a link to the Creative Commons license, and indicate if changes were made. 


\section{References}

Avila A, Alarcon M (1999) Relationship between precipitation chemistry and meteorological situation at a rural site in NE Spain. Atmos Environ 33:1663-1677. https://doi.org/10.1016/S1352-2310(98)00341-0

Botterill LC, Fisher M (2003) Beyond drought: people, policy and perspectives. CSIRO Publishing, Clayton

Brown JF, Wardlow BD, Tadesse T, Hayes MJ, Reed BC (2008) The vegetation drought response index (VegDRI): a new integrated approach for monitoring drought stress in vegetation. GIScience Remote Sens 45:16-46. https://doi.org/10.2747/1548-1603.45.1.16

Cancelliere A, Salas JD (2010) Drought probabilities and return period for annual streamflows series. J Hydrol 391:77-89. https://doi.org/10.1016/j.jhydrol.2010.07.008

Chiew FHS, Piechota TC, Dracup JA, McMahon TA (1998) EL Nino/southern oscillation and Australian rainfall, streamflow and drought: links and potential for forecasting. J Hydrol 204:138-149

Choi KS, Kang SD, Kim HD (2013) Spatiotemporal variability of April rainfall in Korea by western Pacific teleconnection pattern. Int J Climatol 33:1168-1177. https://doi.org/10.1002/joc.3502

Clausen B, Pearson CP (1995) Regional frequency analysis of annual maximum streamflow drought. J Hydrol 173(14):111-130. https://doi.org/10.1016/0022-1694(95)02713-Y

Esteban-Parra MJ, Rodrigo FC, Castro-Diez Y (1998) Spatial and temporal patterns of precipitation in Spain for the period 1880-1992. Int J Climatol 18:1557-1574

Hao Z, Hoa F, Singh VP (2016) A general framework multivariate multi-index drought prediction based on Multivariate Ensemble Streamflow Prediction (MESP). J Hydrol 539:1-10. https://doi.org/10.1016/j. jhydrol.2016.04.074

Huang S, Li P, Huang Q, Leng G, Hou B, Ma L (2017) The propagation from meteorological to hydrological drought and its potential influence factors. J Hydrol 547:184-195. https://doi.org/10.1016/j.jhydr ol.2017.01.041

Jang MW, Chung HW, Choi JY, Park KW, Bae SJ (2004) Development of a single reservoir agricultural drought evaluation model for paddy. J Korean Soc Agric Eng 46(3):17-30. https://doi.org/10.5389/ KSAE.2004.46.3.017

Karamouz M, Rasouli K, Nazif S (2009) Development of a hybrid index for drought prediction: a case study. J Hydrol Eng 14:617-627. https://doi.org/10.1061/(ASCE)HE.1943-5584.0000022

Keyantash J, Dracup JA (2002) The quantification of drought: an evaluation of drought indices. Bull Am Meteorol Soc 83:1167-1180

Kim GS, Lee JW (2011) Evaluation of drought indices using drought records. J Korea Water Resour As 44:639-652. https://doi.org/10.3741/jkwra.2011.44.8.639 (in Korean with English abstract)

Korea Rural Community Corporation (2012) The 2012 drought white paper. Ministry for Food, Agriculture Forestry and Fisheries, p 287 (in Korea)

Korean Ministry of Land, Infrastructure and Transport (2009) Progress on drought preparedness. Ministry of Land, Infrastructure and Transport, p 12 (in Korean)

Kumaz L (2014) Drought in Turkey. Istanbul Policy Center

Kwon HH, Lall U, Kim SJ (2016) The unusual 2013-2015 drought in South Korea in the context of a multicentury precipitation record: inferences from a nonstationary, multivariate, Bayesian copula model. Geophys Res Lett 43:8534-8544. https://doi.org/10.1002/2016GL07027

Lee JW, Jang SS, Ahn SR, Park KW, Kim SJ (2016) Evaluation of the relationship between meteorological, agricultural and in situ big data droughts. J Korean As Geogr Inf Stud 19(1):64-79. https://doi. org/10.11108/kagis.2016.19.1.064 (in Korean with English abstract)

Leng G, Tangand Q, Rayburg S (2015) Climate change impacts on meteorological, agricultural and hydrological droughts in China. Glob Planet Change 126:23-34. https://doi.org/10.1016/j.glopl acha.2015.01.003

Li Z, Hao Z, Shi X, Dery SJ, Li J, Chen S, Li Y (2016) An agricultural drought index to incorporate the irrigation process and reservoir operations. Glob Planet Change 143:10-20. https://doi.org/10.1016/j. gloplacha.2016.05.008

Liu X, Yin ZY (2001) Spatial and temporal variation of summer precipitation over the eastern Tibetan Plateau and the North Atlantic Oscillation. J Clim 14:2896-2909. https://doi.org/10.1175/15200442(2001)014\%3c2896:SATVOS\%3e2.0.CO;2

Mckee TB, Doesken NJ, Kleist J (1993) The relationship of drought frequency and duration to time scales. In: 8th conference on applied climatology, vol 17, pp 179-183

Meshcherskaya AV, Blazhevich VG (1997) The drought and excessive moisture indices in a historical perspective in the principal grain-producing regions of the former Soviet Union. J Clim 10:2670-2682. https://doi.org/10.1175/1520-0442(1997)010\%3c2670:TDAEMI\%3e2.0.CO;2

Mishra AK, Singh VP (2010) A review of drought concepts. J Hydrol 391(1-2):202-216. https://doi. org/10.1016/j.jhydrol.2010.07.012 
Mo KC, Lettenmaier DP (2014) Objective drought classification using multiple land surface models. J Hydrometeorol 15:990-1010. https://doi.org/10.1175/JHM-D-13-071.1

Mo KC, Paegle K, Higgins RW (1997) Atmospheric processes associated with summer flood and drought in the central United States. J Clim 10:3028-3046. https://doi.org/10.1175/1520-0442(1997)010\%3c302 8:APAWSF\%3e2.0.CO;2

Naithani KJ, Ewers BE, Pendall E (2012) Sap flux-scaled transpiration and stomatal conductance response to soil and atmospheric drought in a semi-arid sagebrush ecosystem. J Hydrol 464-465:176-185. https ://doi.org/10.1016/j.jhydrol.2012.07.008

Nam WH, Choi JY, Jang MW, Hong EM (2013) Agricultural drought risk assessment using reservoir drought index. J Korean Soc Agric Eng 55(3):41-49. https://doi.org/10.5389/ksae.2013.55.3.041 (in Korean with English abstract)

NCDC (2016) Billion dollar U.S. weather and climate disaster, 1980-2015. https://www.ncdc.noaa.gov/billi ons/events. Accessed 7 Jan 2016

Nicholson SE (1983) Sub-sahara rainfall in the years 1976-1980: evidence continued drought. Mon Weather Rev 111:1646-1654

Nuissier O, Joly B, Joly A, Ducrocq AJV (2011) A statistical downscaling to identify the large-scale circulation patterns associated with heavy precipitation events over southern France. Q J R Meteorol Soc 137:1812-1827. https://doi.org/10.1002/qj.866

Palmer WC (1965) Meteorological drought. Office of Climatology US, Weather Bureau, Washington

Palmer WC (1968) Keeping track of crop moisture conditions, nationwide: the crop moisture index. Weatherwise 21(4):156-161. https://doi.org/10.1080/004312672.1968.9932814

Powell EJ, Keim BD (2015) Trends in daily temperature and precipitation extremes for southeastern United States: 1948-2012. J Clim 28:1592-1612. https://doi.org/10.1175/JCLI-D-14-00410.1

Rajsekhar D, Singh VP, Mishra AK (2015) Multivariate drought index: an information theory based approach for integrated drought assessment. J Hydrol 526:164-182. https://doi.org/10.1016/j.jhydr ol.2014.11.031

Rencher AC (1998) Multivariate statistical inference and applications. Wiley, Hoboken, p 559

Rossi G (2000) Drought mitigation measures: a comprehensive framework. Adv Natl Technol Hazards Res. https://doi.org/10.1007/978-94-015-9472-1_18

Stoll S, Hendricks-Franssen HJ, Bardossy A, Kinzelbach W (2013) On the relationship between atmospheric circulation patterns, recharge and soil moisture dynamics in Switzerland. J Hydrol 502:1-9. https://doi.org/10.1016/j.jhydrol.2013.08.017

Vasiliades L, Loukas A (2009) Hydrological response to meteorological drought using the Palmer drought indices in Thessaly, Greece. Desalination 237:3-12

Vicente-Serrano SM, Begueria S, Lorenzo-Lacruz J, Camarero JJ, Lopez-Moreno JI, Azorin-Molina C, Revuelto J, Moran-Tejeda E, Sanchez-Lorenzo A (2012) Performance of drought indices for ecological, agricultural, and hydrological applications. Earth Interact 16:1-27. https://doi.org/10.1175/2012E I000434.1

Wang H, Chen Y, Pan Y, Li W (2015) Spatial and temporal variability of drought in the arid region of China and its relationship to teleconnection indices. J Hydrol 523:283-296. https://doi.org/10.1016/j.jhydr ol.2015.01.055

Wilhite DA, Glantz MH (1985) Understanding the drought phenomenon: the role of definitions. Water Int 10:111-120

Yevjevich VL, Cunha D, Vlachos E (1983) Coping with droughts. Water Resources Publications

Yoo J, Kwon HH, Kim TW, Ahn JH (2012) Drought frequency analysis using cluster analysis and bivariate probability distribution. J Hydrol 420-421:102-111. https://doi.org/10.1016/j.jhydrol.2011.11.046

Zhang L, Zhou T (2015) Drought over East Asia: a review. J Clim 28(8):3375-3399. https://doi.org/10.1175/ JCLI-D-14-00259.1

Zhu X, Bothe O, Freadrich K (2010) Summer atmospheric bridging between Europe and East Asia: influences on drought and wetness on the Tibetan Plateau. Quat Int 236:151-157. https://doi.org/10.1016/j. quaint.2010.06.015

Publisher's Note Springer Nature remains neutral with regard to jurisdictional claims in published maps and institutional affiliations. 